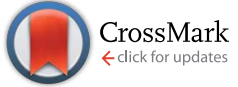

Cite this: J. Mater. Chem. A, 2016, 4, 9941

Received 27th April 2016 Accepted 26th May 2016

DOI: $10.1039 / \mathrm{c} 6 \mathrm{ta0} 3510 \mathrm{~h}$

www.rsc.org/MaterialsA

\section{Highly insensitive and thermostable energetic coordination nanomaterials based on functionalized graphene oxides $\dagger$}

\author{
Qi-Long Yan, ${ }^{a}$ Adva Cohen, ${ }^{a}$ Natan Petrutik, ${ }^{a}$ Avital Shlomovich, ${ }^{2}$ Larisa Burstein, ${ }^{b}$ \\ Si-Ping Pang ${ }^{c}$ and Michael Gozin*a \\ In this research, a group of new energetic coordination nanomaterials (CNMs) based on functionalized \\ graphene oxide sheets (FGS) have been designed and characterized. GO was first functionalized with $\mathrm{N}$ - \\ rich energetic ligands such as triaminoguanidine (TAG), and then the resulting FGS was coordinated with \\ metal ions to prepare energetic CNMs with high thermostability and insensitivity to mechanical stimuli. \\ The density of GO-TAG-Cu(II)/Cu(I) is as high as $3.14 \mathrm{~g} \mathrm{~cm}^{-3}$, while it has a $T_{\mathrm{p}}$ of $495{ }^{\circ} \mathrm{C}$ and $\mathrm{VoD}$ of \\ $7723 \mathrm{~m} \mathrm{~s}^{-1}$ by using $40 \mathrm{wt} \%$ ammonium perchlorate as the oxidant. These insensitive $\left(I_{\mathrm{m}}>81 \mathrm{~J}\right)$ and \\ highly thermostable energetic CNMs in combination with oxidizers are good candidate ingredients of \\ low-vulnerability solid propellants and charges of deep-well perforating guns.
}

\section{Introduction}

The reduced sensitivity and improved thermostability of high performance energetic materials (EMs) are essential requirements for their practical applications. ${ }^{1}$ The EMs are still under fast development in terms of new energetic molecules, novel energetic compositions, advanced energetic composites, as well as unique energetic systems. ${ }^{2}$ There has been a significant amount of EMs being developed during the past decades, including new energetic polymers, ${ }^{3}$ novel nitrocompounds, ${ }^{4}$ energetic salts, ${ }^{5}$ nitrogen rich compounds, based on azole and azine rings, ${ }^{6}$ energetic ionic liquids,${ }^{7}$ nanothermites,${ }^{8}$ energetic supermolecules (host/guest complexes, cocrystals) ${ }^{9}$ and polynitrogen compounds. ${ }^{\mathbf{1 0}}$ However, the newly developed energetic compounds, in most cases, are still not able to completely replace the currently used high EMs due to various problems including chemical incompatibility, instability, high sensitivity, and high cost. As one of the important research topics, the

${ }^{a}$ School of Chemistry, Faculty of Exact Science, Tel Aviv University, Tel Aviv, 69978, Israel.E-mail: cogozin@gmail.com (M. Gozin); terry.well@163.com (Q.-L. Yan); Tel: +972-36405878

${ }^{b}$ Wolfson Applied Materials Research Center, Tel Aviv University, Tel Aviv, 69978, Israel

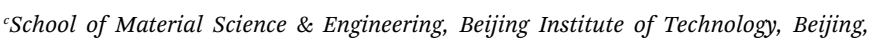
100081, China

$\dagger$ Electronic supplementary information (ESI) available: Descriptions of the experimental details, characterization techniques; figures on the current status of oil extraction perforator charges, XPS spectra and the curves for $\mathrm{Cu} 2 \mathrm{p}$ peaks, SEM images of GO and corresponding EDS results, FTIR of the explored materials, DSC curves of physical mixtures of GO-TAG/Fe(II), GO-TAG/Co(II) and GO-TAG/Ni(II), and a Al-Cu phase diagram; tables on the summary of Raman peak parameters, elemental analysis, FTIR and peak assignments and XPS bonding information. See DOI: 10.1039/c6ta03510h highly thermostable EMs are becoming more and more attractive, since the oil/gas industry is searching for more thermostable explosive charges that could be used in perforator guns for deeper well exploration (Fig. S1 $\dagger$ ). ${ }^{11}$ The currently used thermostable explosives including octahydro-1,3,5,7-tetranitro1,3,5,7-tetrazocine (HMX) with a melting point (m.p.) of $291^{\circ} \mathrm{C}$ (ref. 12) and 1,3,5-triamino-2,4,6-trinitrobenzene (TATB, Scheme 1) with a m.p. of $350{ }^{\circ} \mathrm{C}$ are not sufficiently thermostable to fulfil the upcoming requirements. ${ }^{13}$ There are several strategies for the development of highly thermostable energetic compounds. The most common one is the formation of salts, where the potassium salt of 3,3'-diamino-2,2',4,4',6,6'-hexanitrodiphenylamine (HNDPA, m.p. $=334^{\circ} \mathrm{C}$ ) is a typical example. The second methodology is the introduction of amino groups into the structure of aromatic explosophore. For instance, the introduction of $-\mathrm{NH}_{2}$ groups into a nitrobenzene ring results in more thermostable energetic compounds such as 1,3-diamino2,4,6-trinitro benzene (DATB, m.p. $=286^{\circ} \mathrm{C}$ ) ${ }^{\mathbf{1 4}}$ and TATB. The third strategy is to form conjugations in the molecular structure, where the best example is hexanitrostilbene (HNS), ${ }^{15}$ whose heat resistance can be further enhanced by the introduction of amino groups. ${ }^{16}$ The fourth way is condensation with triazole ring/s, such as picryl-substituted and picrylaminosubstituted 1,2,4-triazoles by condensing 1,2,4-triazole or amino-1,2,4-triazole with picryl. ${ }^{17}$ The insensitive energetic compounds 3-picrylamino-1,2,4-triazole (PATO) and 1,3bis $\left(1^{\prime}, 2^{\prime}, 4^{\prime}\right.$-triazol-3'-ylamino)-2,4,6-trinitrobenzene (BTATNB) with a m.p. of 310 and $320{ }^{\circ} \mathrm{C}$, respectively, are good representatives of this approach. By this strategy, very stable energetic compounds such as 4,4'-bis(1,2,4-triazol-3-ylamino)-2, $2^{\prime}, 3,3^{\prime}, 5$,$5^{\prime}, 6,6^{\prime}$-octanitroazobenzene (BTDAONAB) and 5,5'-bis(2,4,6-trinitrophenyl)-2,2'-bi(1,3,4-oxadiazole) (TKX-55) were prepared 
<smiles>Nc1c([N+](=O)[O-])cc([N+](=O)[O-])c(N)c1[N+](=O)[O-]</smiles><smiles>Nc1c([N+](=O)[O-])cc([N+](=O)[O-])c(N)c1[N+](=O)[O-]</smiles><smiles>O=[N+]([O-])c1cc([N+](=O)[O-])c(Nc2nnc[nH]2)c([N+](=O)[O-])c1</smiles>
BTATNB<smiles>O=[N+]([O-])c1c(N=Nc2c([N+](=O)[O-])c([N+](=O)[O-])c([N+](=O)[O-])c([N+](=O)[O-])c2[N+](=O)[O-])c([N+](=O)[O-])c([N+](=O)[O-])c(Nc2nc[nH]n2)c1[N+](=O)[O-]</smiles><smiles>O=[N+]([O-])c1cc([N+](=O)[O-])c(C=C=Cc2c([N+](=O)[O-])cc([N+](=O)[O-])cc2[N+](=O)[O-])c([N+](=O)[O-])c1</smiles><smiles>O=[N+]([O-])c1cc([N+](=O)[O-])c(Nc2nnc[nH]2)c([N+](=O)[O-])c1Nc1nnc[nH]1</smiles>

Scheme 1 Typical examples of highly thermostable energetic compounds and their molecular structures.

(Scheme 1). ${ }^{18}$ These explosive molecules are symmetric and contain conjugation. BTDAONAB has the unique distinction of being the most thermostable explosive reported so far (with a broad exothermic peak at $\left.550{ }^{\circ} \mathrm{C}\right),{ }^{18 a}$ while TKX-55 normally starts to decompose at $335{ }^{\circ} \mathrm{C} .{ }^{18 b}$ More recently, another thermostable energetic guanidine salt of 3-nitro-1-( $2 H$-tetrazol-5-yl)1H-1,2,4-triazol-5-amine (HANTT) was prepared, which has a decomposition peak temperature of $321^{\circ} \mathrm{C}$, with density $(1.65$ $\mathrm{g} \mathrm{cm}^{-3}$ ) even lower than that of RDX. ${ }^{19}$ However, most of the abovementioned thermostable EMs have not been applied in the perforating guns due to difficult multi-step preparation and low synthetic yields. Recently, alternative superior ways to stabilize the energetic molecules have been developed, including the construction of energetic super structures such as co-crystals and coordination polymers. ${ }^{20}$

It has been also reported that graphene oxide (GO) could stabilize HMX and some other energetic materials, resulting in reduced sensitivity and improved mechanical strength. ${ }^{21}$ In addition to mechanical mixtures, GO was modified into several novel energetic supermolecules, because GO itself is energetic and can readily undergo fast exothermic decomposition. ${ }^{22}$

Typically, GO can be covalently functionalized with selected small molecules or polymers through activation and amidation/ esterification reactions of either the carboxyl or hydroxyl functional groups on the GO surface..$^{23}$ The GO carboxylic acid groups could be first activated by thionyl chloride $\left(\mathrm{SOCl}_{2}\right)$ or by a mixture of 1-ethyl-3-(3-dimethyl-aminopropyl)carbodiimide (EDC) and $N$-hydroxysuccinimide (NHS), followed by the coupling of amines, and the resulting functionalized products were found to be soluble in common organic solvents. ${ }^{24}$ The epoxy groups in GO nanomaterials can also be covalently functionalized with amines. ${ }^{25}$ Alternatively, the noncovalent functionalization of GO can also be accomplished via $\pi-\pi$ stacking, cation $-\pi$, van der Waals interactions, or hydrogen bonding. ${ }^{26}$ In addition, GO has also shown strong oxidizing properties and could be used as an effective oxidant in a broad range of reactions. $^{27}$

Many N-containing compounds are very good ligands in metal coordination chemistry. Among them, diaminoguanidine (DAG) and triaminoguanidine (TAG) are promising ligands, in

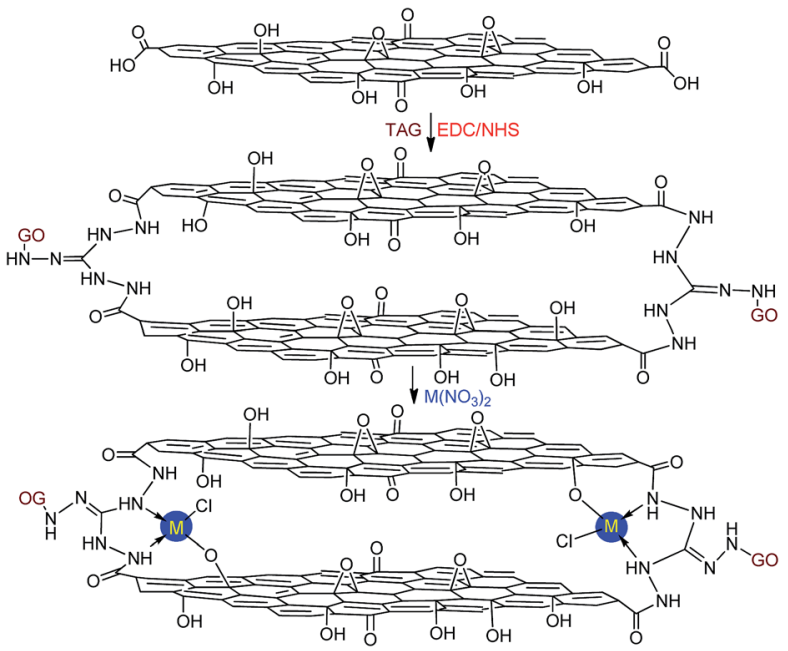

Fig. 1 The GO-TAG-M (M $=\mathrm{Cu}^{2+}, \mathrm{Ni}^{2+}, \mathrm{CO}^{2+}$ and $\left.\mathrm{Fe}^{2+}\right)$ coordination nanomaterials prepared by the reaction of ammonized $\mathrm{GO}$ with corresponding metal nitrates: mononuclear coordination nanomaterials (CNMs) were formed based on the triaminoguanidine (TAG) ligand $(\mathrm{ESI}+)$

protonated, deprotonated and neutral forms depending on their $\mathrm{pH}$ value, binding $\mathrm{Cu}(\mathrm{I})$ or $\mathrm{Cu}(\mathrm{II})$ as the typical metal centers. ${ }^{28}$ The complexes $\mathrm{Cu}(\mathrm{DAG})\left(\mathrm{NO}_{3}\right)_{2}, \mathrm{Cu}(\mathrm{DAG})_{2}\left(\mathrm{NO}_{3}\right)_{2}$, and $\mathrm{Cu}(\mathrm{DAG})_{2}\left(\mathrm{NO}_{3}\right)_{2} \cdot \mathrm{HNO}_{3}$ have been reported, where the DAG ligand is coordinated in the first two compounds. For the latter complex, both the DAG molecule and the $\mathrm{DAGH}^{+}$cation are coordinated ${ }^{29}$ and it was also the case in the $\left[\mathrm{Cu}(\mathrm{DAGH}) \mathrm{Cl}_{3}\right]$ complex. ${ }^{30}$ The reaction between $\mathrm{Cu}\left(\mathrm{NO}_{3}\right)_{2}$ and TAG in aqueous solution results in the formation of the $\mathrm{Cu}(\mathrm{TAG})\left(\mathrm{NO}_{3}\right)_{2}$ complex. ${ }^{29}$ The coordinated compounds containing protonated $\mathrm{TAGH}^{+}$were prepared by the reaction of $\mathrm{CuCl}_{2}$ and TAG in concentrated $\mathrm{HCl} .{ }^{31}$ However, the energetic properties of all the reported metal complexes of DAG and TAG were not explored.

In this work, we report the preparation of novel energetic coordination nanomaterials (CNMs) based on DAG and TAG functionalized GO, using the abovementioned strategies for GO functionalization. In particular, GO-TAG-Cu(I) and GO-TAG$\mathrm{Cu}$ (II) CNMs were synthesized by the amidation process, followed by coordination reactions with $\mathrm{CuCl}$ or $\mathrm{Cu}\left(\mathrm{NO}_{3}\right)_{2}$. This method is facile and avoids the issues of multi-step preparation processes, typical to many other highly thermostable energetic molecules listed in Scheme 1. The first key process is to chemically graft DAG or TAG moieties onto GO flakes by EDC/ NHS coupling. The second process is reacting the functionalized GO flakes (GO-TAG and GO-DAG) with metal ions (Fig. 1), where the resulting structures are supported by characterization of the mononuclear 4-coordinated TAG-Cu(II) complexes.

\section{Experimental section}

\subsection{Materials}

The commercially available graphene oxide (GO, $1-5$ layers) was used as received from the market with an oxygen content of over $42 \%$. Guanidine (99\%), diaminoguanidine (98\%), copper 
nitrate trihydrate (99\%), nickel nitrate (99\%), cuprous chloride (98\%), cobalt nitrate (98\%), iron(II) chloride tetrahydrate (99\%) and hydrazine monohydrate $\left(98 \%, \mathrm{~N}_{2} \mathrm{H}_{4} 64-65 \%\right)$ were obtained from Sigma-Aldrich and stored under nitrogen to prevent oxidation. Ultrapure deionized water (resistivity $>18 \mathrm{M} \Omega$ ) was obtained from a Milli-Q Biocel system. Whatman Anodisc ${ }^{\mathrm{TM}}$ membranes $(0.2 \mu \mathrm{m}$ pore size, $47 \mathrm{~mm}$ diameter $)$ were used during filtration for support of fabricated papers.

\subsection{Preparation of GO-TAG}

$40 \mathrm{mg}$ GO was dispersed in $60 \mathrm{~mL}_{2} \mathrm{O}$ by high power ultrasonication in a glass reactor. $10 \mathrm{~mL}$ aqueous mixed solution of 1-ethyl-3-(3-dimethylaminopropyl)carbodiimide (EDC, $8 \mathrm{mg}$ ) and $N$-hydroxysuccinimide (NHS, $6 \mathrm{mg}$ ) was added to the dispersed GO, and stirred for $30 \mathrm{~min}$. A dark grey agglomeration was formed. Then $400 \mathrm{mg}$ of triaminoguanidine hydrochloride $(\mathrm{TAG} \cdot \mathrm{HCl})$ was added to the obtained mixture in the glass reactor, which should be kept in a water bath at a controlled temperature of $75-80{ }^{\circ} \mathrm{C}$ for four hours with magnetic stirring. Black flocculent precipitates were gradually formed, which were filtered and washed with distilled water three times. The filtered liquid has a $\mathrm{pH}$ value of 1.5-2.0 due to the presence of $\mathrm{HCl}$ molecules. The as-prepared product $(231 \mathrm{mg})$ is the TAG functionalized GO via a bridge of - $\mathrm{CO}-\mathrm{NH}-(\mathrm{GO}-\mathrm{TAG})$.

\subsection{Preparation of GO-TAG-metal coordination nanomaterials}

$120 \mathrm{mg} \mathrm{GO}-\mathrm{TAG}$ was dispersed in $30 \mathrm{~mL} \mathrm{H}_{2} \mathrm{O}$, and then $10 \mathrm{~mL}$ aqueous solution of a certain amount of metal salts can be added to the GO-TAG solution. The metal salts can be $200 \mathrm{mg}$ of $\mathrm{Cu}\left(\mathrm{NO}_{3}\right)_{2}, 199 \mathrm{mg}$ of nickel acetate, $238 \mathrm{mg}$ of $\mathrm{Ni}\left(\mathrm{NO}_{3}\right)_{2}, 163 \mathrm{mg}$ of $\mathrm{FeCl}_{2}, 239 \mathrm{mg}$ of $\mathrm{Co}\left(\mathrm{NO}_{3}\right)_{2}, 121 \mathrm{mg}$ of CuCl or a mixture of 100 $\mathrm{mg} \mathrm{Cu}\left(\mathrm{NO}_{3}\right)_{2}$ with $50 \mathrm{mg} \mathrm{CuCl}$. The mixture was reacted at a temperature of $75{ }^{\circ} \mathrm{C}$ for $5 \mathrm{~h}$. The black precipitates were filtered and washed with $\mathrm{H}_{2} \mathrm{O}$. The obtained filtered liquids have different $\mathrm{pH}$ values: 3.1 for $\mathrm{Cu}\left(\mathrm{NO}_{3}\right)_{2}, 4.5$ for nickel acetate, 3.8 for Ni($\left(\mathrm{NO}_{3}\right)_{2}, 1.6$ for $\mathrm{FeCl}_{2}, 3.7$ for $\mathrm{Co}\left(\mathrm{NO}_{3}\right)_{2}, 3.6$ for $\mathrm{CuCl}$ and 3.5 for mixture of $\mathrm{Cu}\left(\mathrm{NO}_{3}\right)_{2}$ with $\mathrm{CuCl}$. The as-prepared products are coordination nanomaterials: GO-TAG-Cu(II), GO-TAG$\mathrm{Ni}(\mathrm{II})$, GO-TAG-Co(II), GO-TAG-Fe(II), GO-TAG-Cu(I) and GO-TAG-Cu(I)/Cu(II). Only the GO-TAG-Cu(II), GO-TAG-Cu(I) and $\mathrm{GO}-\mathrm{TAG}-\mathrm{Cu}(\mathrm{I}) / \mathrm{Cu}(\mathrm{II})$ are found to be highly thermostable EMs.

\section{Results and discussion}

\subsection{Chemical structure of the ECPs}

Successful TAG functionalization was first confirmed by elemental analysis (EA) and SEM/EDS analysis (Fig. 2), with the compositions and formula listed in Table S1 in the ESI. $\dagger$ As fabricated, $\mathrm{GO}$ has a $\mathrm{C}_{\mathrm{GA}} / \mathrm{O}$ ratio of 2.0, with a water content of less than $3.0 \mathrm{wt} \%$ after drying under vacuum for $48 \mathrm{~h}$. In contrast, the water content for the GO-TAG was slightly increased to $5.3 \mathrm{wt} \%$, while the $\mathrm{C}_{\mathrm{GA}} / \mathrm{O}$ ratio was significantly increased to 4.6 due to the loss of $\mathrm{H}_{2} \mathrm{O}$ during the amidation of carboxyl groups by the TAG moiety. The newly functionalized

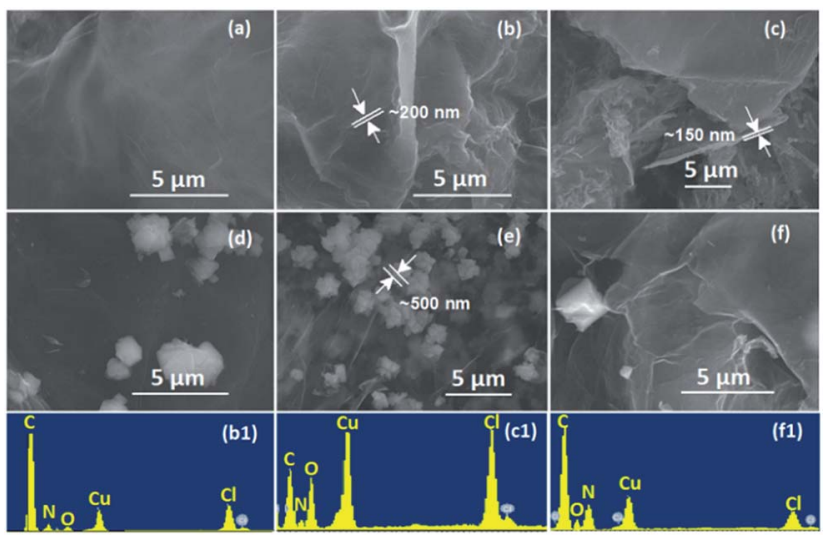

Fig. 2 The SEM images of energetic CNMs: (a) GO-TAG, (b) GOTAG-Cu(॥), (c) GO-TAG-Cu(।) and the GO-complex clusters (d) TAG-Cu(I), (e) TAG-Cu(॥), (f) GO-TAG-Cu(॥)/Cu(I), prepared by simultaneous dispersion of GO-TAG and precipitation of TAG with $\mathrm{Cu}\left(\mathrm{NO}_{3}\right)_{2}, \mathrm{CuCl}$ and their 1:1 aqueous solution (molar ratio), respectively. The EDS surface elemental analyses of the CNMs ( $b, c$ and f) are also included (b1, c1 and f1), which reveal that GO-TAG-Cu(॥) has an atomic $\mathrm{C} / \mathrm{O}$ ratio of $4.6: 1$, and $\mathrm{Cl} / \mathrm{Cu}$ ratio of about $6: 1$. It is due to the significantly reduced oxygen content, as compared to pristine $\mathrm{GO}$ that has an atomic $\mathrm{C} / \mathrm{O}$ ratio of $2: 1$ (Fig. S1, ESI $\dagger$ ). The atomic $\mathrm{O} / \mathrm{N}$ ratio is about $3: 4$, where the $\mathrm{N}$ is due to the functionalization of TAG. The molar ratio of $\mathrm{Cl} / \mathrm{Cu}$ in both $\mathrm{GO}-\mathrm{TAG}-\mathrm{Cu}(\mathrm{I})$ and $\mathrm{GO}-\mathrm{TAG}-\mathrm{Cu}(॥) / \mathrm{Cu}(\mathrm{I})$ materials is $1: 1$.

GO-TAG has a $\mathrm{N}_{\mathrm{TAG}} / \mathrm{C}_{\mathrm{GA}}$ ratio of 0.293. GO-TAG was further coordinated with copper ions.

It has been demonstrated that $\mathrm{TAG} \cdot \mathrm{HCl}$ readily reacts with copper dichloride in concentrated $\mathrm{HCl}$, forming an energetic complex, whose crystal structure is composed of $\left[\mathrm{Cu}_{3}(\mathrm{GO}-\right.$ TAGH) $\left.\mathrm{Cl}_{3}\right]^{+}$cations, $\mathrm{NO}_{3}{ }^{-}$anions and water molecules. ${ }^{31}$ Our materials exhibit a similar coordination chemistry. By examining the morphologies of our CNMs by SEM and EDS (Fig. 2), it is clear that GO-TAG, GO-TAG-Cu(II) and GO-TAG-Cu(I) CNMs are homogeneous materials containing $\mathrm{N}$ and $\mathrm{Cu}$ atoms, indicating successful functionalization and coordination. The molar ratio of $\mathrm{C} / \mathrm{O} / \mathrm{Cu}$ is found to be very different for GO-TAG$\mathrm{Cu}$ (II) and GO-TAG-Cu(I)/Cu(II) CNMs, while the ratio of $\mathrm{Cu} / \mathrm{Cl}$ was maintained to be the same $(1: 1)$, which was also confirmed by XPS analysis of these materials. During functionalization, the GO flakes were linked together by the TAG moiety bridge, resulting in a much higher thickness $(150-200 \mathrm{~nm})$ as compared to $2-5 \mathrm{~nm}$ of stacked GO in $1-5$ layers. ${ }^{24,25}$ The coordination of $\mathrm{Cu}$ (II) did not change the thickness of GO-TAG due to simple doping in the voids between the layers.

The crystal clusters of the TAG-Cu(I) and TAG-Cu(II) complexes were formed on the GO-TAG surfaces when extra TAG $\cdot \mathrm{HCl}$ was added during the complexation reaction. The formed TAG-Cu(I) complex has smaller crystal sizes $(<500 \mathrm{~nm})$ as compared to TAG-Cu(II) complex crystals, with $1-4 \mu \mathrm{m}$ in size. Interestingly, when the $\mathrm{Cu}(\mathrm{I})$ and $\mathrm{Cu}(\mathrm{II})$ ions reacted with GO-TAG in aqueous solution, several crystals were formed on the surface or between the layers of GO-TAG even without using extra TAG $\cdot \mathrm{HCl}$ during complexation. It could be assumed that the reduction of GO-TAG occurred in the presence of $\mathrm{Cu}(\mathrm{I})$ ions 
as a reducing agent, which was then converted to $\mathrm{Cu}$ (II), as confirmed by XPS analysis (Fig. S3 $\dagger$ ). During the reduction, the oxygen functionalities on the surface of GO were almost completely removed and some of the TAG ligands were detached and coordinated with $\mathrm{Cu}$ (II), forming the crystals on the surface. To study the functionalization and the resulting disorder on the GO flakes for energetic GO-TAG-M(II) CNMs, we employed Raman spectroscopy (Fig. 3), and the corresponding peak parameters are summarized in Table $\mathrm{S} 1 . \dagger$

In general, a higher disorder in graphite leads to a broader $\mathrm{G}$ band, as well as to a broad $\mathrm{D}$ band, with relatively higher intensity as compared to the $\mathrm{G}$ band. ${ }^{32}$ The functionalization of GO with TAG and the corresponding metal ion coordination process slightly shift the peak position and largely change the intensity of both $\mathrm{D}$ and $\mathrm{G}$ bands (Table $\mathrm{S} 1 \dagger$ ). All the CNMs based on GO-TAG exhibit a similar couple of Raman-active bands, with the D band inbetween $1343-1350 \mathrm{~cm}^{-1}$, corresponding to a breathing mode of $k$-point photons of $\mathrm{A}_{1 \mathrm{~g}}$ symmetry and the $\mathrm{D}$ band at $1575-1589 \mathrm{~cm}^{-1}$, related to the first order scattering of the $\mathrm{E}_{2 \mathrm{~g}}$ phonon of $\mathrm{sp}^{2}$ in $\mathrm{C}$ atoms. ${ }^{32}$ The $\mathrm{G}$ band of natural graphite could be attributed to the in-phase vibration of the graphite lattice. ${ }^{33}$ After oxidation, the intensity of the $\mathrm{D}$ band is increased, and the G band of GO becomes much broader, owing to the presence of isolated double bonds that resonate at higher frequencies than that of graphite. ${ }^{32,33}$ Two bands could be observed in the samples, in a comparable $\mathrm{D} / \mathrm{G}$ intensity ratio $\left(I_{\mathrm{D}} / I_{\mathrm{G}}\right)$ to that of GO, suggesting that the skeleton structure of GO remains in GO-TAG after functionalization. With the evaporation of the solvent, abundant TAG groups bound to the edges of GO flakes could make GO-TAG nanosheets aggregate together as multi-layered platelets with significantly increased thickness (Fig. 2). The peaks at 273, $279 \mathrm{~cm}^{-1}$ and shoulder peaks correspond to $\mathrm{A}_{\mathrm{g}}$ and $\mathrm{B}_{\mathrm{g}}$ modes of $\mathrm{Cu}-\mathrm{O}$ bonds, while the small bands at around $620 \mathrm{~cm}^{-1}$ are probably due to coordination bonds between $\mathrm{N}$ atoms in the TAG ligand and copper. However, there are no strong peaks observed for nickel(II), cobalt(II) and iron(II) CNMs, which is also the case for glycine
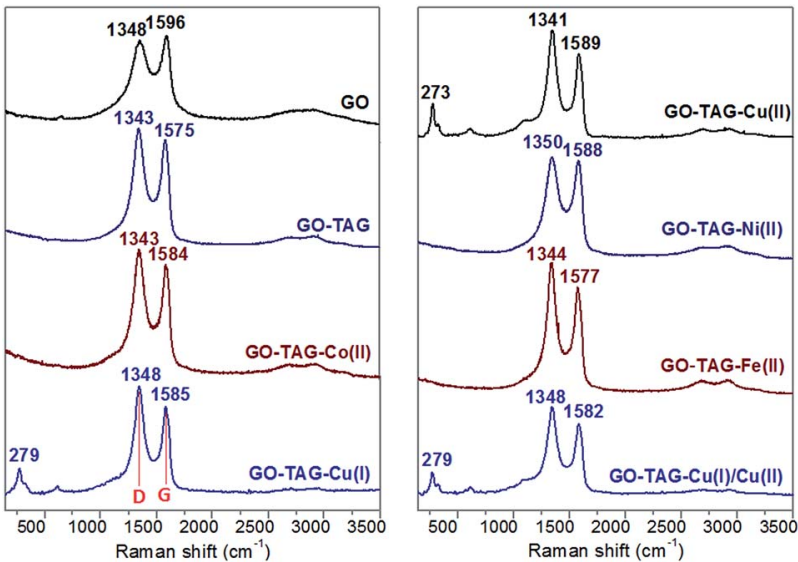

Fig. 3 Raman spectra (using $3.0 \mathrm{~mW}$ laser) with $\mathrm{D}, \mathrm{G}$, and 2D peaks. The decreased $D$ peak intensity of GO compared to TAG functionalized GO (GO-TAG) and its coordinated nanomaterials, indicates more structural defect sites on $\mathrm{GO}$ after functionalization and complexation. functionalized GO during water purification. ${ }^{34}$ One could also notice that the $I_{\mathrm{D}} / I_{\mathrm{G}}$ values for $\mathrm{Ni}$ - and Co-based nanomaterials (Table $\mathrm{S} 1 \dagger$ ) are very close to that of GO-TAG, due to partial van der Waals interactions between the metal ions and the TAGgrafted GO surfaces.

To further address the binding chemistry of GO-TAG with metal ions, in order to generate energetic CNMs, XPS was used. Fig. 4 presents $\mathrm{C} 1 \mathrm{~s}$ and $\mathrm{N}$ 1s curve fitted spectra of GO before and after its functionalization. It shows that the functionalization of GO with the TAG moiety was successful, showing additional peaks for $\mathrm{N}$-bonding (Fig. $\mathrm{S} 3 \dagger$ ). The $\mathrm{C} 1 \mathrm{~s}$ and $\mathrm{N}$ 1s curve fitting also shows the presence of $\mathrm{HO}-\mathrm{C}=\mathrm{O}$ and $-\mathrm{HN}-\mathrm{C}=\mathrm{O}$ bonding components (288.9 and $400.9 \mathrm{eV}$, respectively). It enables direct quantification of the degree of GO functionalization with TAG. ${ }^{35}$ The GO surface oxygen content was reduced during the TAG functionalization and the following coordination processes, causing the disappearance/decrease of the $\mathrm{C}-\mathrm{O}$ (or/and $\mathrm{C}-\mathrm{O}-(\mathrm{C})$ peak, with simultaneous appearance of $\mathrm{C}-\mathrm{N}$, $\mathrm{C}=\mathrm{N},-\mathrm{HN}-\mathrm{C}=\mathrm{O}$ and $\mathrm{C}-\mathrm{O}-\mathrm{Cu}$ peaks (Fig. 4e and $\mathrm{f}$ ). Although $\mathrm{C}-\mathrm{O}$ (or $\mathrm{C}-\mathrm{O}-\mathrm{C}$ ) and $\mathrm{C}=\mathrm{N}$ peaks could be in a close proximity to each other, it is difficult to resolve the observed shift of peak binding energy in the $\mathrm{C}$ 1s structure from $286.6 \mathrm{eV}$ (C-O or/and $\mathrm{C}-\mathrm{O}-(\mathrm{C}))$ to $286.4(\mathrm{C}=\mathrm{N})$. This finding is supported by the observation of the appearance of $\mathrm{C}=\mathrm{N}$ in $\mathrm{N}$ 1s spectra. All these data allow us to deduce that the covalent bonding of TAG- $\mathrm{NH}_{2}$ to $\mathrm{GO}-\mathrm{COOH}$, and the coordination reaction occurred for both GO-TAG-Cu(II) and GO-TAG-Cu(II)/Cu(I). Concurrently, four new peaks corresponding to $\mathrm{C}-\mathrm{N}, \mathrm{C}=\mathrm{N}, \mathrm{NHC}=\mathrm{O}$ and $\mathrm{C}-\mathrm{O}-\mathrm{Cu}$ bonds appear in the $\mathrm{C}$ 1s XPS spectrum for GO-TAG-Cu(II) (Fig. 4b). These chemical bonding types are further confirmed by FTIR analysis (Fig. S4 and Table S3†).

Fig. 5 shows XRD patterns of GO, GO-TAG based ECP materials, and the TAG-Cu(I) complex. The Miller indexing and corresponding plane distance data of our ECP materials are summarized in Table S5† (determined from PXRD spectra by using Jade software). As shown in Fig. 5a, the peak at $10.63^{\circ}$ displays the characteristic peak of GO, corresponding to the Miller plane of 100 with a distance of 8.21 A. The corresponding
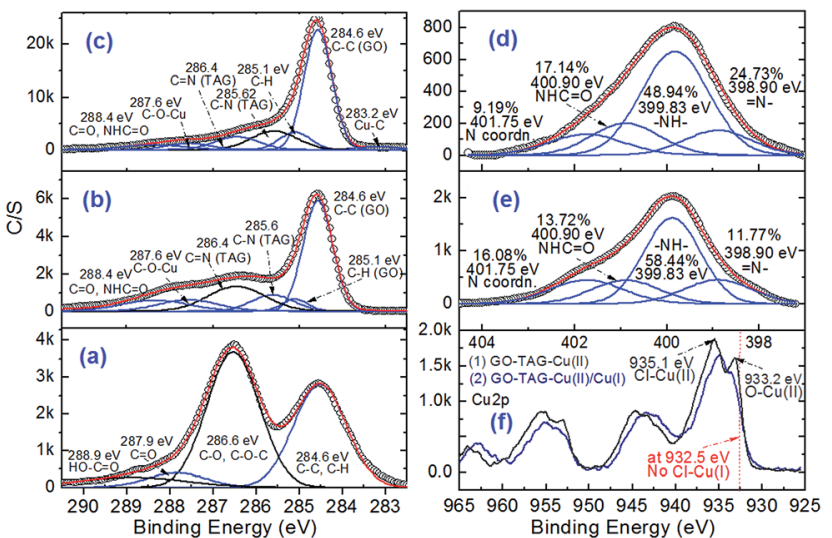

Fig. 4 Deconvolution of the peaks in the XPS spectra for: $\mathrm{C}$ 1s peaks of (a) GO, (b) GO-TAG-Cu(॥), and (c) GO-TAG-Cu(॥)/Cu(I) and $\mathrm{N}$ is peaks of (d) GO-TAG-Cu(॥) and (e) GO-TAG-Cu(॥)/Cu(I), as well as the peaks of (f) $\mathrm{Cu} 2 \mathrm{p}$ for the latter two coordination nanomaterials. 
plane distances for the ECPs are smaller than GO, resulting in higher density (Table 1 ). The peaks at about $43.5^{\circ}$ represent the peak of the graphite phase, with the atom Miller planes indexed as 202 for GO, 131 and 061 for GO-TAG-Cu(II) and GO-TAG$\mathrm{Cu}(\mathrm{II}) / \mathrm{Cu}(\mathrm{I})$, respectively. If we compare the XRD patterns of GObased ECP materials with pristine GO, the difference in the GO/ graphite peak ratio is significant, indicating loss of oxygencontaining groups in GO planes during TAG functionalization, in agreement with the finding that there are more graphitic fractions of GO after the emulsion process. ${ }^{36}$ In the meantime, the peaks representing the GO planes in GO-TAG ECP materials shifted to higher angles. The second and third peaks in the curves (b) and (c) correspond to the $\mathrm{Cu}-\mathrm{Cl}$ complexation structure in these ECPs, which are much different from those of

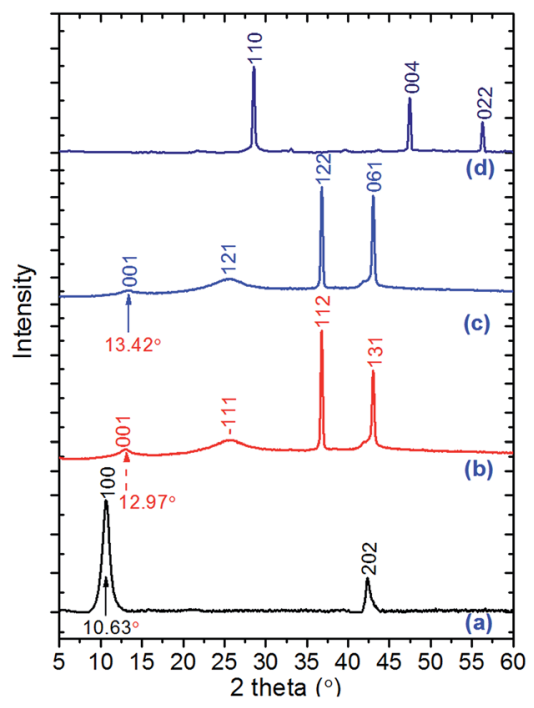

Fig. 5 Experimental powder $\mathrm{X}$-ray spectra of all TAG-Cu(I) and their GO-based ECPs: (a) pristine GO; (b) GO-TAG-Cu(I) ECP; (c) GOTAG-Cu(॥)/Cu(I) ECP; (d) TAG-Cu(I) complex. the pure TAG-Cu(I) complex crystal. The latter complex has a space group of $P 2_{1} / c$ with cell parameters of $a=6.8581(4) \AA$; $b=3.6173(1) \AA ; c=8.3926(2) \AA ; \beta=98.765(5)^{\circ} ; \alpha=\gamma=90^{\circ} ; V=$ 189.42(3) $\AA^{3}$ with $Z=4$. The XRD results further confirmed the successful synthesis of a new structure of GO-TAG ECPs, instead of a mixture of GO with the TAG-Cu(I) complex.

\subsection{Thermal reactivity and stability}

After coordination with metal ions, the hygroscopicity was substantially decreased, especially in the case of GO-TAG$\mathrm{Cu}(\mathrm{II}) / \mathrm{Cu}$ (I) $\mathrm{CNM}$ due to the loss of oxygen functional groups of GO. There is a negligible mass loss for these two CNMs below $140{ }^{\circ} \mathrm{C}$ (Fig. 6c), which was likely due to the increase of their hydrophobicity caused by a decrease in the polar functionality on GO flakes. ${ }^{37}$ The observed rapid mass losses between 180-200 ${ }^{\circ} \mathrm{C}$ for GO and GO-TAG are due to the pyrolysis of the oxygen-containing functional groups. This feature accounts for $25 \%$ of the initial mass of GO, whereas it is about $21 \%$ for GO-TAG, resulting in a slightly higher $\mathrm{C}_{\mathrm{GO}} / \mathrm{O}$ ratio, which is in good agreement with XPS and EDS elemental analysis. The TAG curve of GO-TAG also shows a slow mass-loss process in the temperature range of $310-430{ }^{\circ} \mathrm{C}$ in contrast to pristine GO, which is attributed to the detachment and following thermolysis of the TAG moiety, accompanied by a broad exothermic process (Fig. 6b).

$\mathrm{TAG} \cdot \mathrm{HCl}$ decomposes at about $240{ }^{\circ} \mathrm{C}$ with a heat release of $2310 \mathrm{~J} \mathrm{~g}^{-1}$. For the GO-TAG-Cu(I) and GO-TAG-Cu(II)/Cu(I) CNMs, the endothermic peaks are observed at 255.6 and 262.3 ${ }^{\circ} \mathrm{C}$, corresponding to the loss of water molecules upon reduction of GO. These $\mathrm{H}_{2} \mathrm{O}$ molecules contribute a mass loss of $4.1 \%$, as shown in the TGA curve (Fig. 6c). The large exothermic peaks were covered with a heat release of 1792, 1192, and $847 \mathrm{~J}$ $\mathrm{g}^{-1}$ for GO-TAG-Cu(II), GO-TAG-Cu(I) and GO-TAG-Cu(II)/ $\mathrm{Cu}(\mathrm{I})$, respectively. The lower heat releases of the latter two CNMs again correspond to the slow reduction of the oxygen

Table 1 A comparison of the physical properties, sensitivity and detonation performances of the involved coordination nanomaterials with the TAG-Cu(II) complex, TNT and RDX EMs

\begin{tabular}{|c|c|c|c|c|c|c|c|}
\hline Parameters & GO & $\mathrm{TAG} \cdot \mathrm{HCl}$ & TAG-Cu(I) & CNM(1) & $\mathrm{CNM}(2)$ & TNT & RDX \\
\hline$\% \mathrm{~N}^{a}[\mathrm{wt} \%]$ & $0.91 \%$ & $59.78 \%$ & $25.31 \%$ & $16.80 \%$ & $10.08 \%$ & $18.50 \%$ & $37.84 \%$ \\
\hline$\rho^{c}\left[\mathrm{~g} \mathrm{~cm}^{-1}\right]$ & 1.91 & 1.55 & 3.01 & 2.59 & 3.12 & 1.65 & 1.80 \\
\hline$\Omega \mathrm{CO}_{2}^{d}[\%]$ & $-137.8 \%$ & $-9.1 \%$ & $-4.8 \%$ & $-68.6 \%$ & $-80.6 \%$ & $-74 \%$ & $-21.6 \%$ \\
\hline$\Delta H_{\mathrm{f}}^{e}\left[\mathrm{~kJ} \mathrm{~mol}^{-1}\right]$ & -1869 & +200.2 & -604.2 & -2890.7 & -4486.5 & -59.4 & +83.8 \\
\hline$P_{\mathrm{C}-\mathrm{J}}^{f}[\mathrm{kbar}]$ & $375^{h}$ & 178 & 133 & $267^{i}$ & $232^{i}$ & 213 & 349 \\
\hline $\operatorname{VoD}^{g^{2}}\left[\mathrm{~m} \mathrm{~s}^{-1}\right]$ & $3836^{h}$ & 7198 & 3783 & $7815^{i}$ & $7723^{i}$ & 7304 & 8795 \\
\hline
\end{tabular}

${ }^{a}$ Nitrogen content. ${ }^{b}$ Decomposition peak temperature from DSC $\left(\beta=10^{\circ} \mathrm{C} \min ^{-1}\right) \cdot{ }^{c}$ The density was measured by Helium-Pycnometer, $25{ }^{\circ} \mathrm{C}$. ${ }^{d}$ Oxygen balance (for $\mathrm{C}_{a} \mathrm{H}_{b} \mathrm{~N}_{c} \mathrm{O}_{d}$ compounds, $\left.\Omega=1600 \times(a-2 b-0.5 d) / M_{\mathrm{w}}\right) .{ }^{e}$ Calculated enthalpy of formation. ${ }^{f}$ Detonation pressure. ${ }^{g}$ Detonation velocity. ${ }^{h}$ The pure GO is not detonable, and the detonation parameters were calculated for a mixture of 80 wt $\%$ of GO with 20 wt $\%$ of aluminum. ${ }^{i}$ The detonation performances is compositions containing $40 \mathrm{wt} \% \mathrm{AP}$ and $60 \mathrm{wt} \%$ of the $\mathrm{CNMs}$; CNM(1) and $\mathrm{CNM}(1)$ represent GO-TAG-Cu(II) with formula of $\mathrm{C}_{41} \mathrm{H}_{16} \mathrm{O}_{9}\left(\mathrm{C}_{2} \mathrm{H}_{10} \mathrm{~N}_{12}\right) \mathrm{Cl}_{1.5} \mathrm{Cu}_{1.5}$ and GO-TAG-Cu(II)/Cu(I) with formula of $\mathrm{C}_{42} \mathrm{H}_{13} \mathrm{O}_{8}\left(\mathrm{CH}_{5} \mathrm{~N}_{6}\right) \mathrm{ClCu}$, respectively. TAG-Cu(I) is the complex prepared in aqueous solution of copper nitrate with $\mathrm{TAG} \cdot \mathrm{HCl}$ under room temperature with a formulae of $\mathrm{Cu}_{2}\left(\mathrm{CN}_{6} \mathrm{H}_{4}\right) \mathrm{Cl}_{2} \cdot \mathrm{H}_{2} \mathrm{O}$, where $\mathrm{Cu}(\mathrm{II})$ ions in the starting materials was reduced to $\mathrm{Cu}(\mathrm{I})$. 

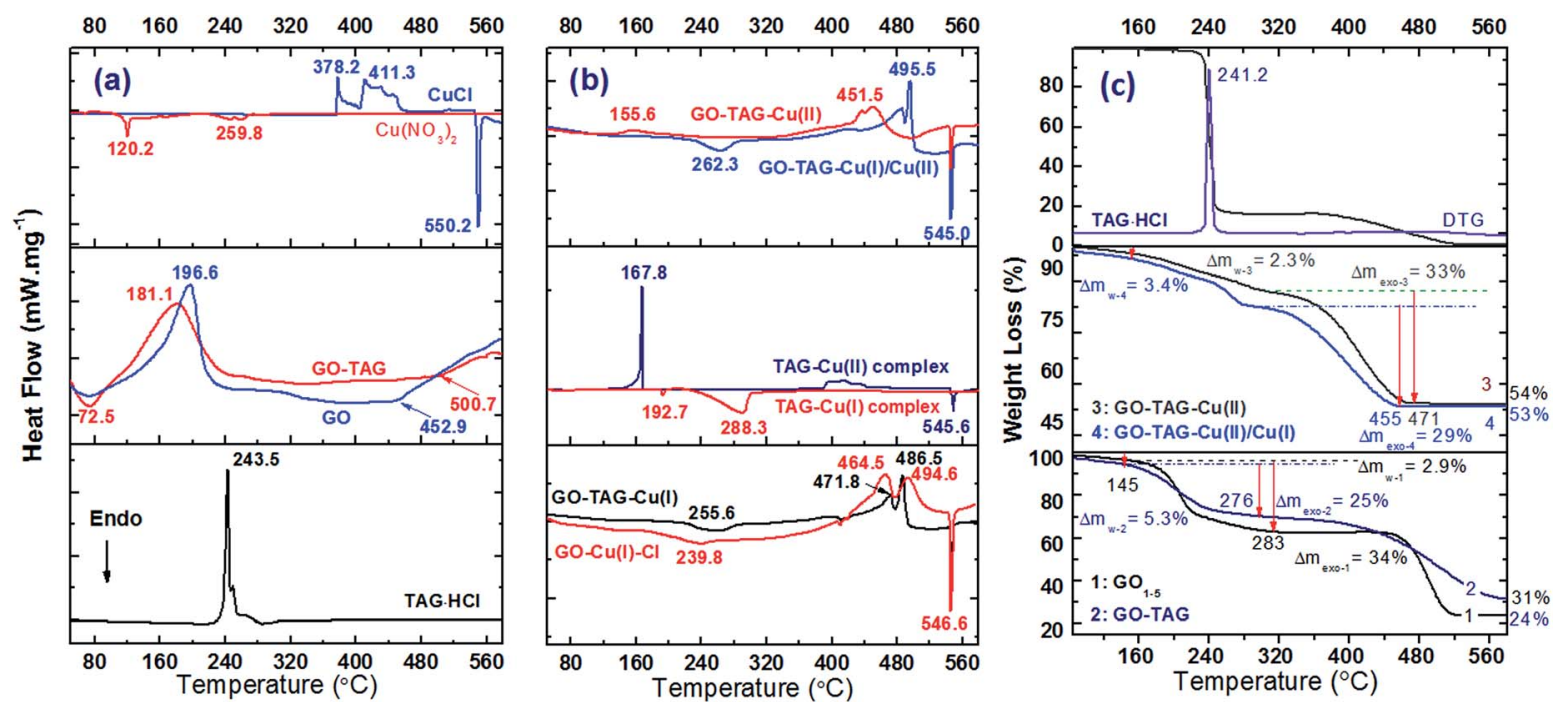

Fig. 6 DSC (a, b) and TGA curves (c) of GO, GO-DAG, GO-TAG and their coordination complexes at a heating rate of $10^{\circ} \mathrm{C} \mathrm{min}{ }^{-1}$. The TAG$\mathrm{Cu}\left(\right.$ II) complex was prepared at room temperature with the $1: 1$ molar ratio of the starting materials according to the literature ${ }^{31}\left(T_{\mathrm{p}}=167.8^{\circ} \mathrm{C}\right)$, while GO-TAG-Cu(॥) CNMs are much more stable with the exothermic peak temperature above $450{ }^{\circ} \mathrm{C}$. The TGA experiments are in good agreement with the DSC findings, and the residues of the CNMs are over $53 \%$ in contrast to $24 \%$ for pristine GO, confirming the presence of copper in the GO-TAG-based CNMs.

functional groups by $\mathrm{Cu}(\mathrm{I})$. In comparison, the decomposition of nickel(II)-, cobalt(II)- and iron(II)-based materials show almost the same decomposition peak as GO-TAG in the temperature range of $170-200{ }^{\circ} \mathrm{C}$ (Fig. S5 $\dagger$ ), which further supports the partial physisorption of these metal ions on the GO-TAG surface. However, there is a weak exothermic peak for iron(II)based materials, probably due to coordination with the TAG ligand. There is a sharp endothermic peak in all cases at about $545-547{ }^{\circ} \mathrm{C}$, due to the phase transition of the $\mathrm{CuAl}_{2}$ alloy (Fig. S6†), which is also the case for the solid-state reaction of $\mathrm{CuCl}$ with metallic $\mathrm{Al}$ upon heating (Fig. 6a). We assume that $\mathrm{CuCl}$ and $\mathrm{CuO}$ are the main decomposition products of the described CNMs. These products could be further reduced in the presence of metallic Al to metallic copper upon heating. In the case of functionalized GO with DAG, further coordination was not so successful for all metals, although DAG could readily react with $\mathrm{Cu}$ (II) ions, forming an energetic complex with two exothermic peaks at above $250{ }^{\circ} \mathrm{C}$ (Fig. S5 $\dagger$ ).

\subsection{Detonation performances and mechanical sensitivity}

In order to predict the detonation performance of our new energetic CNMs, the EXPLO-5 software was used based on the experimental heat of formation $\left(\Delta H_{\mathrm{f}}\right)$ and density $(\rho)$ data (Table 1). As shown in Table 1, pristine GO is not detonable due to low energy output and low achievable detonation temperature. When $20 \mathrm{wt} \%$ of high energy fuel $\mathrm{Al}$ was mixed with GO, the detonation velocity (VoD) was calculated to be $3836 \mathrm{~m} \mathrm{~s}^{-1}$, close to that of a blasting agent. EXPLO- 5 could not calculate VoDs of our CNMs in a single phase due to their very high oxygen deficiency $(<-68 \%)$, indicating that our CNMs are fuel-rich EMs, which need to be combined with oxidants such as ammonium perchlorate (AP). In a subsequent calculation, when $40 \mathrm{wt} \%$ of
AP was added to our CNMs, the calculated VoDs for GO-TAG$\mathrm{Cu}(\mathrm{II})$ and GO-TAG-Cu(II) are 7815 and $7723 \mathrm{~m} \mathrm{~s}^{-1}$, respectively. These VoD parameters are lower than that of 1,3,5-trinitro-1,3,5triazacyclohexane (RDX, $8750 \mathrm{~m} \mathrm{~s}^{-1}$ at a density of $1.76 \mathrm{~g} \mathrm{~cm}^{-3}$ ). The density of GO-TAG-Cu(II)/Cu(I) $\left(3.14 \mathrm{~g} \mathrm{~cm}^{-3}\right)$ is even higher than that of its parent TAG-Cu(II) complex. It is also significantly higher than that of pristine GO and GO-TAG-Cu(II), due to the largely reduced oxygen functional groups on the surface of GO. More importantly, as highly thermostable EMs, our CNMs have much higher VoDs than the most commonly used highly thermostable insensitive EMs, including HNS $(7000 \mathrm{~m}$ $\mathrm{s}^{-1}$ ) and TATB (7350 $\left.\mathrm{m} \mathrm{s}^{-1}\right)$. Our CNMs are also different in their sensitivity to impact due to the change in the amount of oxygen functional groups. GO-TAG- $\mathrm{Cu}(\mathrm{II}) / \mathrm{Cu}(\mathrm{I})$ is more sensitive than GO-TAG-Cu(II), but both of them could be clearly classified as insensitive EMs with excellent impact sensitivity, which is much lower than that of TAG $\cdot \mathrm{HCl}$ and the TAG-Cu(I) complex (Table 1). We believe that our CNMs have a potential to be used as energetic catalysts for solid rocket propellants due to the presence of copper. Moreover, because GO could be fully consumed by oxidation during high temperature combustion of propellants with improved oxygen balance, our CNMs can contribute to the fuel energy density. In fact, the functionalized GO was found to be a promising catalyst for the combustion of nitromethane,$^{38}$ and the presence of nucleophilic oxygen-containing functionalities on the surfaces and edges of our CNMs could be also chemically active sites with catalytic behavior for the combustion of solid propellants. ${ }^{39}$

\section{Conclusions}

The EDC/NHS coupling agent can be used for the functionalization of GO with the TAG moiety, and further coordination 
reaction with metal ions leads to the formation of highly thermostable CNMs. These CNMs are very oxygen deficient $(<-68 \%)$ and should be combined with oxidizers for applications such as explosive charges and as combustion catalysts for solid propellants. Our CNMs GO-TAG-Cu(II) and GO-TAG-Cu(II)/ $\mathrm{Cu}(\mathrm{I})$ have VoDs of 7815 and $7723 \mathrm{~m} \mathrm{~s}^{-1}$, respectively, when $40 \%$ of AP was added as the oxidant. More importantly, our CNMs are very insensitive $\left(I_{\mathrm{m}}>81 \mathrm{~J}\right)$ and thermostable up to more than $450{ }^{\circ} \mathrm{C}$, which is much higher than that of TATB and HNS.

\section{Conflict of interest}

The authors declare no competing financial interests.

\section{Abbreviations}

$\begin{array}{ll}\text { VoD } & \text { Detonation velocity. } \\ \text { EMs } & \text { Energetic materials. } \\ \text { CNMs } & \text { Coordination nanomaterials. } \\ \text { GO } & \text { Graphene oxide. }\end{array}$

\section{Acknowledgements}

The financial support from the Planning and Budgeting Committee (PBC) of the Council for Higher Education in Israeli government is greatly appreciated. This work was also partially supported by the Center for Nanoscience and Nanotechnology and by the Faculty of Exact Sciences in Tel Aviv University.

\section{References}

1 J. P. Agrawal, High Energy Materials, Propellants Explos. Pyrotech, Wiley-VCH, Germany, 2010.

2 M. B. Talawar, S. K. Jangid, T. Nath, R. K. Sinha and S. N. Asthana, J. Hazard. Mater., 2015, 300, 307-321.

3 (a) B. Gaur, B. Lochab, V. Choudhary and I. K. Varma, J. Macromol. Sci., Polym. Rev., 2003, 43, 505-545; (b) Q.-L. Yan, S. Zeman and A. Elbeih, Thermochim. Acta, 2012, 537, 1-12.

4 (a) J. Zhang, Q. Zhang, T. T. Vo, D. A. Parrish and J. M. Shreeve, J. Am. Chem. Soc., 2015, 137, 1697-1704; (b) J. Zhang and J. M. Shreeve, J. Am. Chem. Soc., 2014, 136, 4437-4445; (c) P. Yin, D. A. Parrish and J. M. Shreeve, J. Am. Chem. Soc., 2015, 137, 4778-4786.

5 (a) H. Gao and J. M. Shreeve, Chem. Rev., 2011, 111, 7377; (b) J. Zhang, L. A. Mitchell, D. A. Parrish and J. M. Shreeve, J. Am. Chem. Soc., 2015, 137, 10532-10535; (c) Y.-L. Wang, F.-Q. Zhao, Y.-P. Ji, Q.-L. Yan, J.-H. Yi, S.-Y. Xu, et al., J. Anal. Appl. Pyrolysis, 2014, 105, 295-300.

6 (a) Y. Li, J. Hao, H. Liu, S. Lu and J. S. Tse, Phys. Rev. Lett., 2015, 115, 105502; (b) A. A. Dippold and T. M. Klapötke, J. Am. Chem. Soc., 2013, 135, 9931-9938; (c) T. M. Klapötke and T. G. Witkowski, Propellants, Explos., Pyrotech., 2015, 40, 366-373.
7 R. P. Singh, R. D. Verma, D. T. Meshri and J. M. Shreeve, Angew. Chem., Int. Ed., 2006, 45, 3584-3601.

8 M. Comet, G. Vidick, F. Schnell, Y. Suma, B. Baps and D. Spitzer, Angew. Chem., Int. Ed., 2015, 54, 4458-4462.

9 (a) K. Liu, G. Zhang, J. Luan, Z. Chen, P. Su and Y. Shu, J. Mol. Struct., 2016, 1110, 91-96; (b) J. C. Bennion, A. McBain, S. F. Son and A. J. Matzger, Cryst. Growth Des., 2015, 15, 2545. 10 (a) B. Tan, M. Huang, X. Long, J. Li, X. Yuan and R. Xu, Int. J. Quantum Chem., 2015, 115, 84-89; (b) C. Knapp and J. Passmore, Angew. Chem., Int. Ed., 2004, 43, 4834-4836; (c) M. T. Nguyen, Coord. Chem. Rev., 2003, 244, 93-113.

11 G. Sun, X. Wang, F. Sun and Y. Liang, Explos. Mater., 2002, $31,4$.

12 T. R. Gibbs and A. Popolato, LASL Explosive Property Data, University of California Press, Los Angeles, 1980, vol. 38, p. 157.

13 A. J. Bellamy, S. J. Ward and P. Golding, Propellants, Explos., Pyrotech., 2002, 27, 49-58.

14 S. Zeman, Thermochim. Acta, 1993, 216, 157-168.

15 (a) C. X. Lu, Kogyo Kayaku, 1990, 51, 275-279; (b) K. G. Shipp, P. Golding and G. F. Hayes, Propellants Explos., 1979, 4, 115120.

16 J. P. Agrawal, Cent. Eur. J. Energ. Mater., 2012, 9, 273-290.

17 (a) J. Li, B. Chen and Z. Ou, Proc. 17th Int. Pyrotech. Seminar, Beijing lnst. Tech. Press, Beijing, vol. 1, 1991, pp. 196-199; (b) J. P. Agrawal, M. U. S. Prasad and R. N. Surve, New J. Chem., 2000, 24, 583-585.

18 (a) S. N. Mehilal, A. K. Sikder and J. P. Agrawal, Indian J. Eng. Mater. Sci., 2004, 11, 516-520; (b) T. M. Klapötke and T. Witkowski, ChemPlusChem, 2016, 81, 357-360.

19 C. Bian, M. Zhang, C. Li and Z. Zhou, J. Mater. Chem. A, 2015, 3, 163-169.

20 J. P. Agrawal, M. R. N. Surve, and V. K. Bapat, et.al., HEMRL Report No. HEMRL/99/6, 1999.

21 (a) R. Li, J. Wang, J. P. Shen, C. Hua and G. C. Yang, Propellants, Explos., Pyrotech., 2013, 38, 798-804; (b) P. D. McCrary, P. A. Beasley, S. A. Alaniz, C. S. Griggs, R. M. Frazier and R. D. Rogers, Angew. Chem., Int. Ed., 2012, 51, 9784-9787; (c) X. Zhang, W. M. Hikal, Y. Zhang, S. K. Bhattacharia, L. Li, S. Panditrao, et al., Appl. Phys. Lett., 2013, 102, 141905; (d) Y. Zhang, Z. Shao, K. Gao, $\mathrm{X} . \mathrm{Wu}$ and Y. Liu, Integr. Ferroelectr., 2014, 154, 147-153.

22 (a) Q.-L. Yan, M. Gozin, F.-Q. Zhao, A. Cohen and S.-P. Pang, Nanoscale, 2016, 8, 4799-4851; (b) V. Alain-Rizzo, L. Galmiche, P. Audebert, F. Miomandre, G. Louarn, Bozlar, et al., Chem. Mater., 2015, 27, 4298-4310; (c) A. Dimiev, D. V. Kosynkin, L. B. Alemany, P. Chaguine and J. M. Tour, J. Am. Chem. Soc., 2012, 134, 2815-2822.

23 (a) S. Niyogi, E. Bekyarova, M. E. Itkis, J. L. McWilliams, M. A. Hamon and R. C. Haddon, J. Am. Chem. Soc., 2006, 128, 7720; (b) J. Azevedo, L. Fillaud, C. Bourdillon, J.-M. Noël, F. Kanoufi, et al., J. Am. Chem. Soc., 2014, 136, 4833-4836.

24 (a) B. Wang, B. Luo, M. Liang, A. Wang, J. Wang, Y. Fang, et al., Nanoscale, 2011, 3, 5059-5066; (b) J. Hwang, T. Yoon, S. H. Jin, J. Lee, T.-S. Kim, S. H. Hong and S. Jeon, Adv. Mater., 2013, 25, 6724-6729; (c) O. C. Compton, 
D. A. Dikin, K. W. Putz, L. C. Brinson and S. T. Nguyen, $A d v$. Mater., 2010, 22, 892-896.

25 H. F. Yang, C. S. Shan, F. H. Li, D. X. Han, Q. X. Zhang and L. Niu, Chem. Commun., 2009, 3880.

26 C. H. Lu, H. H. Yang, C. L. Zhu, X. Chen and G. N. Chen, Angew. Chem., Int. Ed., 2009, 48, 4785.

27 H. P. Jia, D. R. Dreyer and C. W. Bielawski, Tetrahedron, 2011, 67, 4431.

28 G. R. Andrade, J. Kunsminskas, L. Pizzuti, A. Dos Anjos, S. D. Inglez, B. Tirloni and P. H. Suegama, Inorg. Chem. Commun., 2015, 61, 210-213.

29 Z. A. Saveleva, S. V. Larionov and V. N. Ikorskii, Izvestiya SO RAN SSSR, Ser. Khim. Nauk., 1982, 2, 89.

30 Z. A. Saveleva, S. V. Larionov, G. V. Romanenko, N. V. Podberezskaya, O. V. Shishkin and Y. T. Struchkov, Zh. Strukt. Khim., 1995, 36, 936.

31 A. Z. Saveleva, V. G. Romanenko, A. L. Sheludyakova and V. S. Larionov, Polyhedron, 2000, 19, 1737-1740.

32 K. N. Kudin, B. Ozbas, H. C. Schniepp, R. K. Prudhomme, I. A. Aksay and R. Car, Nano Lett., 2008, 8, 36-41.
33 D. D. Zhang, S. Z. Zu and B. H. Han, Carbon, 2009, 47, 29933000.

34 (a) F. Najafi, O. Moradi, M. Rajabi, M. Asif, I. Tyagi, S. Agarwal and V. K. Gupta, J. Mol. Liq., 2015, 208, 106113; (b) F. Fang, L. Kong, J. Huang, S. Wu, K. Zhang, J. Wang, et al., J. Hazard. Mater., 2014, 270, 1-10.

35 (a) N. L. V. Carreño, M. T. Escote, A. Valentini, L. McCafferty, V. Stolojan, Beliatis, et al., Nanoscale, 2015, 7, 17441-17449; (b) A. Y. S. Eng, C. K. Chua and M. Pumera, Nanoscale, 2015, 7, 20256-20266.

36 H. V. Kumar, S. J. Woltornist and D. H. Adamson, Carbon, 2016, 98, 491-495.

37 (a) S. Stankovich, D. A. Dikin, R. D. Piner, K. A. Kohlhaas, A. Kleinhammes, Y. Jia, et al., Carbon, 2007, 45, 1558-1565; (b) O. C. Compton, B. Jain, D. A. Dikin, A. Abouimrane, K. Amine and S. T. Nguyen, ACS Nano, 2011, 5, 4380-4391.

38 J. L. Sabourin, D. M. Dabbs, R. A. Yetter, F. L. Dryer and I. A. Aksay, ACS Nano, 2009, 3, 3945-3954.

39 J. D. Fowler, M. J. Allen, V. C. Tung, Y. Yang, R. B. Kaner and B. H. Weiller, ACS Nano, 2009, 3, 301-306. 